EXTENDED REPORT

\title{
Myocardial perfusion scintigraphy and coronary disease risk factors in systemic lupus erythematosus
}

\author{
E M C Sella, E I Sato, W A Leite, J A Oliveira Filho, A Barbieri
}

Ann Rheum Dis 2003;62:1066-1070

See end of article for authors' affiliations

Correspondence to

Professor E I Sato,

Universidade Federal de

São Paulo, Escola Paulista de Medicina,

Reumatologia, Rua

Botucatu 740-Vila

Clementino, CEP 04023

900, São Paulo, Brazil;

emiliasato@

reumato.epm.br

Accepted 28 April 2003

\begin{abstract}
Objective: To evaluate the prevalence of myocardial perfusion abnormalities and the possible association between myocardial perfusion defects and traditional coronary artery disease (CAD) risk factors as well as systemic lupus erythematosus (SLE) related risk factors.

Patients and methods: Female patients with SLE, disease duration $>5$ years, age 18-55 years, who had used steroids for at least one year were enrolled. Traditional CAD risk factors evaluated were arterial hypertension, diabetes mellitus, dyslipidaemia, postmenopausal status, smoking, obesity, and premature family CAD profile. Myocardial perfusion scintigraphy was evaluated by single photon emission computed tomography with technetium $99 \mathrm{~m}$-sestamibi at rest and after dipyridamole induced stress.

Results: Eight two female patients with SLE without angina pectoris with mean (SD) age 37 (10) years, disease duration 127 (57) months, SLE Disease Activity Index (SLEDAl) score 6 (5), and SLICC/ACR-DI score 2 (2) were evaluated. Myocardial perfusion abnormalities were found in 23 patients (28\%). The mean (SD) number of CAD risk factors was 2.2 (1.6). There was a significant positive correlation between age and number of CAD risk factors. Lower high density lipoprotein (HDL) cholesterol level showed a significant association with abnormal scintigraphy. Logistic regression analysis showed that lower HDL cholesterol level and diabetes mellitus were associated with myocardial perfusion abnormalities. Current vasculitis was also associated with abnormal scintigraphy.

Conclusions: Lower HDL cholesterol level and diabetes mellitus have a significant influence on abnormal myocardial perfusion results found in asymptomatic patients with SLE. Current vasculitis was associated with abnormal myocardial scintigraphy. These data suggest that abnormal myocardial scintigraphy may be related to subclinical atherosclerosis.
\end{abstract}

$\mathrm{T}$ he survival of patients with systemic lupus erythematosus (SLE) has improved in the past three decades. Despite the improved survival patients with SLE still die at a rate that is three times greater than that of the general population. ${ }^{1}$ Many studies have shown that premature atherosclerosis is one of the major causes of morbidity and mortality in these patients..$^{2-4}$

Angina pectoris has been reported to occur in up to $12 \%$ of patients, ${ }^{3-7}$ acute myocardial infarction (MI) in up to $16 \%,{ }^{3}{ }^{7-10}$ and sudden death in up to $8 \% .^{8}{ }^{10-12}$ Manzi et al reported a 52 times higher risk for cardiovascular disease in young women with SLE than in controls matched for age and sex in the Framingham Study. ${ }^{7}$ The rate of acute MI as the primary cause of death in SLE has been reported to be up to $36 \%$ in various studies. ${ }^{26}{ }^{10-16}$ Esdaile et al showed that the risk for all relevant cardiovascular outcomes was higher in patients with SLE even after accounting for all traditional Framingham risk factors. ${ }^{17}$

In addition to the traditional coronary artery disease (CAD) risk factors, inflammatory, immunological, metabolic, and haemostatic factors have been described as independent risk factors for premature CAD in patients with SLE. Homocysteine levels $^{18} 19$ and antiphospholipid antibodies ${ }^{2021}$ are some of these factors. Other potential mechanisms for coronary ischaemia, such as vasculitis, ${ }^{22}{ }^{23}$ immune complex deposition, ${ }^{24}$ microvascular disease, ${ }^{25}$ intracoronary thrombus, ${ }^{26}$ and coronary aneurysms, ${ }^{27-29}$ may also contribute to acute coronary events. Longer duration of SLE, older age at SLE diagnosis, and steroid treatment are also SLE disease related factors that seem to contribute to CAD..$^{6-8}$

There is no consensus about the best diagnostic method for subclinical CAD in patients with SLE, but the ability of vascular imaging techniques to measure atherosclerosis in subclinical stages may allow better risk stratification. ${ }^{30-32}$

The objective of this study was to evaluate the prevalence of myocardial perfusion abnormalities in asymptomatic female patients with SLE. The secondary objectives were to evaluate the possible association between myocardial perfusion defects and traditional CAD risk factors, age, and the number of American College of Rheumatology (ACR) criteria, vasculitis history, presence of anticardiolipin (aCL) antibody, the Systemic Lupus Erythematosus Disease Activity Index (SLEDAI) score, Systemic Lupus International Collaborating Clinics/American College of Rheumatology Damage Index for systemic lupus erythematosus (SLICC/ACR-DI) score, duration of prednisone use, and cumulative prednisone dosage.

\section{PATIENTS AND METHODS}

Patients with SLE were enrolled from the outpatient clinic of the rheumatology division of the Universidade Federal de São Paulo/Escola Paulista de Medicina between September 1998 and September 2000.

The inclusion criteria were SLE classification according to ACR criteria, ${ }^{33}{ }^{34}$ female sex, age 18-55 years, disease duration $>5$ years, and prednisone use for at least one year. Exclusion
Abbreviations: aCL, anticardiolipin; $\mathrm{ACR}$, American College of Rheumatology; $B M I$, body mass index; $C A D$, coronary artery disease; $\mathrm{Cl}$, confidence interval; $\mathrm{ECG}$, electrocardiography; $\mathrm{HDL}$, high density lipoprotein; LDL, low density lipoprotein; MI, myocardial infarction; OR, odds ratio; SLE, systemic lupus erythematosus; SLEDAI, Systemic Lupus Erythematosus Disease Activity Index; SLICC/ACR-DI, Systemic Lupus International Collaborating Clinics/American College of Rheumatology Damage Index; SPECT, single photon emission computed tomography 
criteria were contraindications for the dipyridamole proto$\mathrm{col}^{35}$ current or previous acute MI, history of angina pectoris, coronary interventions (coronary catheterisation, coronary artery bypass surgery, or percutaneous transluminal coronary angioplasty), pregnancy, and nursing.

Blood and urine samples were obtained from the patients and the following laboratory tests carried out: glucose, cholesterol, triglyceride, blood cell count, anti-dsDNA antibody, serum complement, aCL antibody, and urine analysis. Global disease activity was assessed by the SLEDAI score. ${ }^{36}$ All patients were examined and their clinical charts were reviewed to obtain clinical and serological data and to calculate the SLICC/ACR-DI score. ${ }^{37} 38$ Total cumulative dosage and duration of prednisone use were calculated in patients with SLE, followed up regularly at the rheumatology division with intervals between evaluations not exceeding four months since diagnosis.

Traditional CAD risk factors considered were arterial hypertension (blood pressure $\geqslant 140 \times 90 \mathrm{~mm} \mathrm{Hg}$ or use of antihypertensive drugs), diabetes mellitus (fasting glucose $\geqslant 7.0 \mathrm{mmol} / \mathrm{l}$, use of insulin or oral hypoglycaemic agents), dyslipidaemia (high density lipoprotein (HDL) cholesterol $<0.90 \mathrm{mmol} / \mathrm{l}$, low density lipoprotein (LDL) cholesterol $\geqslant 3.35 \mathrm{mmol} / \mathrm{l}$, triglyceride level $\geqslant 2.26 \mathrm{mmol} / \mathrm{l})$, postmenopausal status, current smoking, obesity (body mass index $\left.(\mathrm{BMI}) \geqslant 30 \mathrm{~kg} / \mathrm{m}^{2}\right)$, and premature family CAD profile (definite acute MI or sudden death before age 55 in first degree male relatives and before age 65 in first degree female relatives). ${ }^{39-42}$

Myocardial perfusion scintigraphy was evaluated using single photon emission computed tomography (SPECT) with technetium-99m-sestamibi ( ${ }^{99 \mathrm{~m}}$ Tc-sestamibi) as radiotracer. A two phase, one day protocol was used, with images being captured at rest and after dipyridamole induced stress. After 12 lead electrocardiography (ECG) performed at rest, patients received $8 \mathrm{mCi}$ of ${ }^{99 \mathrm{~m}}$ Tc-sestamibi (Cardiolite; Du Pont Merck Pharmaceutical, USA) given as an intravenous bolus. Myocardial images at rest were acquired after one hour. Two hours later, pharmacological cardiac stress was induced in patients with $0.56 \mathrm{mg} / \mathrm{kg}$ of dipyridamole (Persantin; Boehringer Ingelheim, Argentina) infused for four minutes. Seven minutes after infusion, $24 \mathrm{mCi}$ of ${ }^{99 \mathrm{~m}} \mathrm{Tc}$-sestamibi was injected as an intravenous bolus. During and after pharmacological stress, heart rate, blood pressure, ECG results, and symptoms were monitored at one minute intervals. After one hour, SPECT images were again obtained. A cardiologist was in attendance to supervise the pharmacological stress test. The test was concluded prematurely according to the following conventional clinical criteria: 2nd or 3rd grade atrioventricular blockade, systolic hypotension $\leqslant 80 \mathrm{~mm} \mathrm{Hg}$, ST segment fall $\geqslant 2 \mathrm{~mm}$, angina pectoris, headache, hyperventilation, and/or gastrointestinal symptoms. ${ }^{35}$ Patients who had cardiac or vascular symptoms received $120 \mathrm{mg}$ of aminophylline (Aminofilina; Novartis Biociências, Brazil). ${ }^{43}$

All patients were asked to abstain from smoking and alcoholic and caffeine products for 24 hours before the perfusion test. Drugs containing methylxanthine (aminophylline, pentoxyphylline, and theophylline), calcium channel blockers, and $\beta$ blockers were also stopped 48 hours before the procedure. ${ }^{44}$ ST segment alterations during or after dipyridamole infusion were considered significant if ST deviations were $\geqslant 1 \mathrm{~mm}$ compared with baseline ECG. If the ST segment was abnormal in the resting ECG, the result of the dipyridamole test was considered to be abnormal if any additional deviation was $\geqslant 2 \mathrm{~mm}$.

A tomographic gammacamera (APEX SPX-4/4HR, Elscint, Israel) was used to acquire myocardial scintigraphy images. Data were acquired as 60 frames, 20 seconds per frame, according to the current conventional clinical protocol.
Resting ${ }^{99 \mathrm{~m}}$ Tc-sestamibi and stress induced myocardial perfusion images were reconstructed using routine clinical protocols. Perfusion images were displayed as short axis, vertical long axis, and horizontal long axis tomograms for assessment of perfusion defects. Three expert observers unaware of the patient's clinical history and CAD risk factor profile performed the image analysis. The test was defined as normal if no regional hypoconcentration was found in two series evaluated. Abnormalities were considered to be reversible (suggestive of ischaemia) if they were found only after stress, and fixed (suggestive of fibrosis) if they were present both at rest and after stress.

The ethics committee of Universidade Federal de São Paulo/Escola Paulista de Medicina approved this study, and all patients signed an informed consent term before enrolment.

\section{Statistical analysis}

The $\chi^{2}$ test, $\chi^{2}$ Pearson test, and Fisher test were used to analyse qualitative variables. The $t$ test was used to analyse quantitative variables, and Spearman's correlation was used to verify correlation between two variables. ${ }^{45}$ A logistic regression model was performed to evaluate the influence of different variables on myocardial perfusion abnormalities. ${ }^{46}$ A p value $<0.05$ was considered significant and a $p$ value between 0.05 and 0.10 was considered a tendency towards significance.

\section{RESULTS}

Eight two patients (59\% were white), with a mean (SD) age of 37 (10) years and mean (SD) disease duration 127 (57) months, were studied. The mean (SD) age at the time of SLE diagnosis was 27 (9) years, with a median of 25 years.

The mean SLEDAI score was 6 (5) and the mean SLICC/ ACR-DI score was 2 (2). Only four (5\%) patients had four ACR criteria, seven (9\%) had five criteria, 23 (28\%) had six, $20(24 \%)$ had seven, and 28 (34\%) had eight or more criteria. The prevalence of different clinical and laboratory features (according to ACR criteria) was: malar rash in $90 \%$, discoid rash in $23 \%$, photosensitivity in $89 \%$, oral ulcers in $37 \%$, arthritis in $88 \%$, serositis in $37 \%$, renal disorder in $49 \%$, neurological disorder in $11 \%$, haematological disorder in $88 \%$, immunological disorders in $82 \%$, and antinuclear antibodies in $99 \%$.

Seventy patients $(85 \%)$ presented at least one CAD risk factor and $30(37 \%)$ patients had at least three risk factors at the time of the study. Patients had a mean (SD) of 2.2 (1.6) traditional risk factors. A positive correlation was found between age and the number of CAD risk factors $\left(r_{\mathrm{s}}=0.482\right)$. The most common CAD risk factors were arterial hypertension (40\%), higher LDL cholesterol level (32\%), current smoking $(32 \%)$, and postmenopausal status $(28 \%)$.

Myocardial perfusion abnormalities were found in 23 $(28 \%)$ patients. Fifty six per cent of the total myocardial defects were reversible, $20 \%$ were fixed, and $24 \%$ were reversible and fixed defects. We found a tendency towards an association between the number of CAD risk factors and myocardial perfusion abnormalities $(\mathrm{p}=0.054)$.

A lower HDL cholesterol level was found in $10 \%$ of patients with normal scintigraphy and in $30 \%$ of patients with an abnormal test (odds ratio $(\mathrm{OR})=3.86, \mathrm{p}=0.04$ ) (table 1 ). Total cholesterol, HDL cholesterol, LDL cholesterol, very low density lipoprotein (VLDL) cholesterol, triglyceride, and BMI were analysed in patients with normal and abnormal myocardial perfusion scintigraphy. The mean BMI of patients with perfusion defects was significantly higher than the mean BMI of patients with normal results $\left(28 \mathrm{~kg} / \mathrm{m}^{2} \vee 24 \mathrm{~kg} / \mathrm{m}^{2}\right.$, $\mathrm{p}=0.02$ ). Excluding BMI, we did not find significant difference between patients with or without perfusion defects. 
Table 1 Association between CAD risk factors and myocardial perfusion scintigraphy in 82 patients with SLE

\begin{tabular}{|c|c|c|c|c|c|}
\hline CAD risk factors & $\begin{array}{l}\text { Normal MIBI } \\
\text { (n=59) } \\
\text { No }(\%)\end{array}$ & $\begin{array}{l}\text { Abnormal MIBI } \\
(\mathrm{n}=23) \\
\text { No }(\%)\end{array}$ & p Value & OR & $95 \% \mathrm{Cl}$ \\
\hline Hypertension† $(n=33)$ & $20(34)$ & $13(57)$ & 0.06 & 2.53 & 0.95 to 6.79 \\
\hline Diabetes mellitus $\ddagger(n=5)$ & $2(3)$ & 3 (13) & 0.13 & 4.27 & 0.67 to 27.47 \\
\hline $\begin{array}{l}\text { HDL cholesterol }<0.9 \mathrm{mmol} / \mp \\
(\mathrm{n}=13)\end{array}$ & $6(10)$ & $7(30)$ & $0.04^{*}$ & 3.86 & 1.13 to 13.16 \\
\hline $\begin{array}{l}\mathrm{LDL} \text { cholesterol } \geqslant 3.35 \mathrm{mmol} / \mathrm{I} \dagger \\
(\mathrm{n}=26)\end{array}$ & $20(34)$ & $6(26)$ & 0.50 & 0.69 & 0.23 to 2.02 \\
\hline $\begin{array}{l}\text { Triglyceride } \geqslant 2.26 \mathrm{mmol} / \$ \\
(n=16)\end{array}$ & $12(20)$ & $4(17)$ & 1 & 1.21 & 0.35 to 4.24 \\
\hline Postmenopausal $†(n=23)$ & $16(27)$ & $7(30)$ & 0.76 & 1.18 & 0.41 to 3.39 \\
\hline Smokingt $(n=26)$ & $20(34)$ & $6(26)$ & 0.50 & 0.69 & 0.23 to 2.02 \\
\hline Obesity $\ddagger(n=16)$ & 9 (15) & $7(30)$ & 0.13 & 0.41 & 0.13 to 1.28 \\
\hline CAD family history $\ddagger(n=12)$ & $8(14)$ & $4(17)$ & 0.73 & 0.74 & 0.20 to 2.76 \\
\hline
\end{tabular}

Logistic regression analysis with classic coronary risk factors and age at study showed that lower HDL cholesterol level $(\mathrm{OR}=4.58,95 \%$ confidence interval $(\mathrm{CI}) 1.31$ to 15.96 $(\mathrm{p}=0.017))$ and diabetes mellitus $(\mathrm{OR}=5.88,95 \%$ CI 0.89 to $38.95(\mathrm{p}=0.066))$ were associated with myocardial perfusion abnormalities in our patients. Other logistic regression analysis was also performed taking into account the number of ACR criteria, digital vasculitis, and other types of vasculitis (except mucous or digital vasculitis) found at chart review, current aCL antibody, actual vasculitis, SLEDAI score, SLICC/ ACR-DI score, and a number of traditional CAD risk factors. The analysis showed that current vasculitis was the important variable in the final model for myocardial perfusion abnormalities $(\mathrm{OR}=3.86,95 \%$ CI 1.13 to 13.16 $(\mathrm{p}=0.031))$.

There was a positive correlation between digital vasculitis at chart review and the number of ACR criteria $\left(r_{\mathrm{s}}=0.326\right)$, and between digital vasculitis at chart review and actual vasculitis $\left(r_{\mathrm{s}}=0.424\right)$.

Forty three of 82 patients with SLE were regularly followed up at the institution after diagnosis, at intervals of $\leqslant 4$ months. Twenty eight $(65 \%)$ of these patients had a normal myocardial perfusion study and 15 (35\%) had an abnormal test. No association was found between abnormal myocardial perfusion and the cumulative prednisone dose $(p=0.185)$ or duration of prednisone use $(p=0.095)$ in this subgroup of patients.

\section{DISCUSSION}

Subclinical heart disease has been reported to be an independent predictor of CAD risk in the general population. Women with subclinical disease were at greater risk for acute MI. ${ }^{47}$ Early investigation for CAD in the preclinical stage in young women with SLE is justified because cardiovascular events are an important cause of morbidity and mortality in this population. Published reports show that coronary disease (angina pectoris or acute MI) is more common in women with SLE than in the general population. Moreover, the mean age of patients with SLE who had coronary disease was younger than seen in the general population. ${ }^{4}$

We studied patients with more than five years of SLE, who had used steroids for at least one year, in attempt to evaluate patients at a greater risk for CAD. ${ }^{10} 111648$ We analysed only asymptomatic patients, because we wanted to investigate subclinical heart disease. We also excluded patients older than 55 years, because women after this age have higher risk for CAD than younger women in a general population.

Longer steroid use was associated with a poor outcome in three studies. ${ }^{6-8} \mathrm{~A}$ high steroid dose also seems to be associated with a poor prognosis in patients with SLE. ${ }^{49}$ Longer steroid treatment and greater cumulative prednisone dose showed a significant association with atherosclerotic plaque in carotid arteries..$^{50}$ On the other hand, the duration of prednisone treatment may be related to the duration of SLE and higher prednisone use may be related to a more severe disease. ${ }^{51}$ We did not find significant difference in prednisone use, duration or cumulative steroid dosage between patients with SLE with normal or abnormal myocardial scintigraphy. Rahman et $a l^{52}$ reported that the incidence of premature CAD in patients with SLE independent of steroid use was greater $(4.5 / 1000)$ than that observed in the Framingham Heart Study (2.8/1000 women).

Our results were similar to those reported by Petri et al, ${ }^{53}$ who found at least one CAD risk factor in $97 \%$ of 225 patients evaluated. The most prevalent CAD risk factor was a sedentary life style (70\%). Hypercholesterolaemia was found in $56 \%$, arterial hypertension in $41 \%$, family history of premature CAD in $41 \%$, and obesity in $38 \%$. They also found $53 \%$ of patients with at least three of these traditional risk factors.

In the current study, patients with abnormal scintigraphy had 2.6 (1.7) risk factors, showing the role of risk factors in the scintigraphy abnormality. Bruce et al found a mean of 1.8 (1.0) CAD risk factors in a series of patients with SLE, ${ }^{54}$ and Rahman et al reported that patients with SLE and CAD had $2.0(0.8)$ risk factors at the time of the cardiovascular event. ${ }^{55}$

The frequency of myocardial perfusion abnormalities in our study was lower than that reported by Hosenpud et al $(38 \%)^{56}$ and Bruce et al $(40 \%) .^{57}$ Hosenpud et al evaluated 26 patients younger than 50 years, irrespective of their previous cardiac history. ${ }^{56}$ Bruce et al evaluated 130 consecutive patients independent of CAD risk factors or coronary disease history and included older patients. ${ }^{57}$ On the other hand, Schillaci $e t$ al and Sun et al found a high proportion of asymptomatic patients with abnormal myocardial scintigraphy. ${ }^{58} 59$ Schillaci et al studied 28 young patients with SLE without CAD risk factors and without CAD symptoms, and reported $64 \%$ with abnormal scintigraphy. ${ }^{58}$ Sun et al studied 28 asymptomatic patients with SLE and observed $43 \%$ with an abnormal myocardial perfusion test. ${ }^{59}$ Most of the perfusion defects in our study were reversible, as also reported by Hosenpud et $a^{56}$ and Bruce et al. ${ }^{57}$

Considering the result of the myocardial perfusion study as a dependent variable, and current age, traditional CAD risk factors, and SLE related risk factors as independent variables, we performed logistic regression analysis using several models. Lower HDL cholesterol level and diabetes mellitus were the classic risk factors with most influence on the myocardial perfusion scintigraphy results. Bruce et al also had 
noted that HDL cholesterol level was an important risk factor for myocardial perfusion abnormality. ${ }^{60}$

Logistic regression analysis including SLE related coronary risk factors showed that current vasculitis was associated with myocardial perfusion abnormality, suggesting that the vascular inflammatory process may have a role in abnormal myocardial perfusion.

We do not know if myocardial perfusion abnormalities represent the presence of atherosclerotic disease or just an endothelial dysfunction, an early stage of the atherosclerosis. To define the real cause of scintigraphic abnormalities it will be necessary to perform a coronary angiography in these patients. There are no reported studies showing that abnormal myocardial scintigraphy represents atherosclerotic plaque. However, the significant association between lower HDL cholesterol level and abnormal scintigraphy strongly suggests that myocardial perfusion defects may represent an early atherosclerotic process.

This study showed the important effects of traditional CAD risk factors and some SLE related coronary risk factors such as vasculitis on the results of myocardial scintigraphy. Lower HDL cholesterol level and diabetes mellitus were the variables associated with myocardial perfusion abnormalities in our patients. Actual vasculitis was the most important SLE related variable associated with abnormal myocardial perfusion.

Knowledge of the role of atherosclerosis in morbidity and mortality in patients with SLE shows the importance of recognising and controlling modifiable coronary risk factors even in asymptomatic young women with SLE.

\section{ACKNOWLEDGEMENTS}

We thank Gilberto Alonso and Marta M Sevillano, members of the nuclear medicine division of the Universidade Federal de São Paulo/ Escola Paulista de Medicina, who read the scintigraphy results. Financial support for the work: Fundação de Amparo à Pesquisa do Estado de São Paulo (FAPESP) project 98/11794-6.

\section{Authors' affiliations}

E M C Sella, E I Sato, Rheumatology Division, Universidade Federal de São Paulo, Escola Paulista de Medicina, Brazil

W A Leite, J A Oliveira Filho, Cardiology Division, Universidade Federal de São Paulo, Escola Paulista de Medicina, Brazil

A Barbieri, Image Department, Universidade Federal de São Paulo, Escola Paulista de Medicina, Brazil

\section{REFERENCES}

1 Gladman DD, Urowitz MB. Prognosis, mortality and morbidity in systemic lupus erythematosus. In: Wallace DJ, Hahn BH, eds. Dubois' lupus erythematosus, 6th ed. Philadelphia: Lippincott Williams \& Wilkins, 2001:1255-73

2 Ginzler E, Berg A. Mortality in systemic lupus erythematosus. J Rheumatol 1987; 14(suppl 13):218-22.

3 Gladman DD, Urowitz MB. Morbidity in systemic lupus erythematosus. J Rheumatol 1987; 14(suppl 13):223-6.

4 Urowitz MB, Gladman DD. Evolving spectrum of mortality and morbidity in SLE. Lupus 1999:8:253-5.

5 Badui E, Garcia-Rubi D, Robles E, Jimenez J, Juan L, Deleze M, et al. Cardiovascular manifestations in systemic lupus erythematosus: prospective study of 100 patients. Angiology 1985;36:431-41.

6 Jonsson H, Nived O, Sturfelt G. Outcome in systemic lupus erythematosus: a prospective study of patients from a defined population. Medicine (Baltimore) 1989:68:141-50

7 Manzi S, Meilahn EN, Rairie JE, Conte CG, Medsger TA Jr, JansenMcWilliams $L$, et al. Áge-specific incidence rates of myocardial infarction and angina in women with systemic lupus erythematosus: comparison with the Framingham study. Am J Epidemiol 1997:145:408-15.

8 Petri M, Perez-Gutthann S, Spence D, Hochberg MC. Risk factors for coronary artery disease in patients with systemic lupus erythematosus. Am J Med 1992;93:513-19.

9 Sturfelt G, Eskilsson J, Nived O, Truedsson L, Valind S. Cardiovascular disease in systemic lupus erythematosus: a study of 75 patients from a defined population. Medicine (Baltimore) 1992;71:216-23.

10 Abu-Shakra M, Urowitz MB, Gladman DD, Gough J. Mortality studies in systemic lupus erythematosus: results from a single center - I. Causes of death J Rheumatol 1995:22:1259-64.
11 Ward MM, Pyun E, Studenski S. Causes of death in systemic lupus erythematosus: long-term followup of an inception cohort. Arthritis Rheum 1995;38: 1492-9

12 Jacobsen S, Petersen J, Ullman S, Junker P, Voss A, Rasmussen JM, et al. Mortality and causes of death of 513 Danish patients with systemic lupus erythematosus. Scand J Rheumatol 1999;28:75-80.

13 Urowitz MB, Bookman AAM, Koehler BE, Gordon DA, Smythe HA, Ogryzlo MA. The bimodal mortality pattern of systemic lupus erythematosus. Am J Med 1976:60:221-5.

14 Rosner S, Ginzler EM, Diamond HS, Weiner M, Schlesinger M, Fries JF, et al. A multicenter study of outcome in systemic lupus erythematosus: II. Causes of death. Arthritis Rheum 1982;25:612-17.

15 Helve T. Prevalence and mortality rates of systemic lupus erythematosus and causes of death in SLE patients in Finland. Scand J Rheumatol 1985;14:43-6.

16 Rubin LA, Urowitz MB, Gladman DD. Mortality in systemic lupus erythematosus: the bimodal pattern revisited. Q J Med 1985;55:87-98.

17 Esdaile JM, Abrahamowicz M, Grodzicky T, Li Y, Panaritis C, du Berger R, et al. Traditional Framingham risk factors fail to fully account for accelerated atherosclerosis in systemic lupus erythematosus. Arthritis Rheum 2001; 44:2331-7.

18 Petri M, Roubenoff R, Dallal GE, Nadeau MR, Selhub J, Rosenberg IH. Plasma homocysteine as a risk factor for atherothrombotic events in systemic lupus erythematosus. Lancet 1996;348:1120-4.

19 Fijnheer R, Roest M, Haas FJLM, De Groot PG, Derksen RH. Homocysteine, methylenetetrahydrofolate reductase polymorphism, antiphospholipid antibodies, and thromboembolic events in systemic lupus erythematosus: a retrospective cohort study. J Rheumatol 1998;25:1737-42.

20 Asherson RA, Khamashta MA, Baguley E, Oakley CM, Rowell NR, Hughes GR. Myocardial infarction and antiphospholipid antibodies in SLE and related disorders. Q J Med 1989;73:1103-15.

21 De Bandt M, Benali K, Guillevin L, Hachulla E, Job C, Fautrel B, et al. Longitudinal determination of antiphospholipid antibodies in lupus patients without previous manifestations of antiphospholipid syndrome: a prospective study. J Rheumatol 1999;26:91-6.

22 Bonfiglio TA, Botti RE, Hagstrom JWC. Coronary arteritis, occlusion, and myocardial infarction due to lupus erythematosus. Am Heart $J$ 1972;83:153-8.

23 Homcy CJ, Liberthson RR, Fallon JT, Gross S, Miller LM. Ischemic heart disease in systemic lupus erythematosus in the young patient: report of six cases. Am J Cardiol 1982:49:478-84.

24 Korbet SM, Schwartz MM, Lewis EJ. Immune complex deposition and coronary vasculitis in systemic lupus erythematosus: report of two cases. Am J Med 1984;77:141-6.

25 Rangel A, Lavalle C, Chávez E, Jimenez M, Acosta JL, Badui E, et al. Myocardial infarction in patients with systemic lupus erythematosus with normal findings from coronary arteriography and without coronary vasculitis: case reports. Angiology 1999;50:245-53.

26 Kutom AH, Gibbs HR. Myocardial infarction due to intracoronary thrombi without significant coronary artery disease in systemic lupus erythematosus. Chest 1991; 100:571-2

27 Sumino H, Kanda T, Sasaki T, Kanazawa N, Takeuchi H. Myocardial infarction secondary to coronary aneurysm in systemic lupus erythematosus: an autopsy case. Angiology 1995;46:527-30.

28 Nobrega TP, Klodas E, Breen JF, Liggett SP, Higano ST, Reeder GS. Giant coronary artery aneurysms and myocardial infarction in a patient with systemic lupus erythematosus. Cathet Cardiovasc Diagn 1996;39:75-9.

29 Koh HK, Yoo DH, Yoo TS, Jun JB, Jung SS, Lee JU, et al. Coexistence of coronary aneurysms and total occlusion of coronary arteries in systemic lupus erythematosus. Clin Exp Rheumatol 1998;16:739-42.

30 Aranow C, Ginzler EM. Epidemiology of cardiovascular disease in systemic lupus erythematosus. Lupus 2000;9:166-9.

31 Bruce IN, Gladman DD, Urowitz MB. Systemic lupus erythematosus: premature atherosclerosis in systemic lupus erythematosus. Rheum Dis Clin North Am 2000;26:257-78.

32 Manzi S, Kuller LH, Edmundowicz D, Sutton-Tyrrell K. Vascular imaging: changing the face of cardiovascular research. Lupus 2000;9:176-82.

33 Tan EM, Cohen AS, Fries JF, Masi AT, McShane DJ, Rothfield NF, et al. The 1982 revised criteria for the classification of systemic lupus erythematosus. Arthritis Rheum 1982;25:1271-7.

34 Hochberg MC. Updating the American College of Rheumatology revised criteria for the classification of systemic lupus erythematosus. Arthritis Rheum $1997 \cdot 40 \cdot 1725$

35 Departamento de Ergometria e Reabilitação Cardiovascular da Sociedade Brasileira de Cardiologia. Consenso Nacional de Ergometria. Arq Bras Cardiol 1995;65:189-211.

36 Bombardier C, Gladman DD, Urowitz MB, Caron D, Chang CH, Committee on prognosis studies in SLE. Derivation of the SLEDAI: a disease activity index for lupus patients. Arthritis Rheum 1992;35:630-40.

37 Gladman D, Ginzler E, Goldsmith C, Fortin P, Liang M, Urowitz M, et al. The development and initial validation of the systemic lupus international collaborating clinics/American College of Rheumatology damage index for systemic lupus erythematosus. Arthritis Rheum 1996:39:363-9.

38 Gladman DD, Urowitz MB, Goldsmith CH, Fortin P, Ginzler E, Gordon C, et al. The reliability of the systemic lupus international collaborating clinics/ American College of Rheumatology damage index in patients with systemic lupus erythematosus. Arthritis Rheum 1997:40:809-813.

39 Expert Panel on detection, evaluation, and treatment of high blood cholesterol in adults. Summary of the second report of the National Cholesterol Education Program expert panel on detection, evaluation, and treatment of high blood cholesterol in adults (adult treatment panel II). JAMA $1993 \cdot 269 \cdot 3015-23$ 
40 Expert Panel on detection, evaluation, and treatment of high blood cholesterol in adults. National Cholesterol Education Program: second report of the expert panel on detection, evaluation, and treatment of high blood cholesterol in adults (adult treatment panel II). Circulation 1994:89:1329-445.

41 Sociedade Brasileira de Cardiologia. Segundo Consenso Brasileiro sobre dislipidemias - avaliação, detecção e tratamento. Arq Bras Cardiol 1996;67:109-28.

42 European Society of Cardiology, European Atherosclerosis Society, European Society of Hypertension, International Society of Behavioural Medicine, European Society of General Practice/Family Medicine, European Heart Network. Prevention of coronary heart disease in clinical practice: recommendations of the second Joint Task Force of European and other societies on coronary prevention. Eur Heart J 1998;19:1434-503.

43 Botvinick EH, Dae MW. Dipyridamole perfusion scintigraphy. Semin Nucl Med 1991;21:242-65.

44 American College of Cardiology/American Heart Association Task Force on Assessment of Diagnostic and Therapeutic Cardiovascular Procedures (Committee on Radionuclide Imaging)/American Society of Nuclear Cardiology. Guidelines for clinical use of cardiac radionuclide imaging. J Am Coll Cardiol 1995;25:521-47.

45 Siegel J. Estatística não-paramétrica. Brasil: McGraw Hill do Brasil, 1981:350.

46 Kelsey JL, Hwittemore AS, Evans AS, Thompson WD. Methods in observational epidemiology, 2nd ed. Oxford: Oxford University Press, 1996:432.

47 Kuller LH, Shemanski L, Psaty BM, Borhani NO, Gardin J, Haan MN, et al. Subclinical disease as an independent risk factor for cardiovascular disease. Circulation 1995:92:720-6.

48 Urowitz MB, Gladman DD. Late mortality in SLE: "the price we pay for control". J Rheumatol 1980;7:412-16.

49 Massardo L, Martínez ME, Jacobelli S, Villarroel L, Rosenberg H, Rivero S. Survival of Chilean patients with systemic lupus erythematosus. Semin Arthritis Rheum 1994:24:1-11.

50 Manzi S, Selzer F, Sutton-Tyrrell K, Fitzgerald SG, Rairie JE, Tracy RP, et al. Prevalence and risk factors of carotid plaque in women with systemic lupus erythematosus. Arthritis Rheum 1999;42:51-60.
51 Petri $M$. Detection of coronary artery disease and the role of traditional risk factors in the Hopkins lupus cohort. Lupus 2000;9:170-5.

52 Rahman P, Gladman DD, Urowitz MB. Premature coronary artery disease in systemic lupus erythematosus in the absence of corticosteroid use. J Rheumatol 2000;27:1323-5

53 Petri $M$, Spence D, Bone LR, Hochberg MC. Coronary artery disease risk factors in the Johns Hopkins lupus cohort: prevalence, recognition by patients, and preventive practices. Medicine (Baltimore) 1992;71:291-302.

54 Bruce IN, Urowitz MB, lbanez D, Steiner G, Gladman DD. The prevalence of "Framingham risk factors" for coronary artery disease in women with SLE: a cohort control study [abstract]. Arthritis Rheum 2000;43(suppl):S246, (abstr 1080).

55 Rahman P, Urowitz MB, Gladman DD, Bruce IN, Genest J Jr. Contribution of traditional risk factors to coronary artery disease in patients with systemic lupus erythematosus. J Rheumatol 1999;26:2363-8.

56 Hosenpud JD, Montanaro A, Hart MV, Haines JE, Specht HD, Bennett RM, et al. Myocardial perfusion abnormalities in asymptomatic patients with systemic lupus erythematosus. Am J Med 1984;77:286-92.

57 Bruce IN, Burns RJ, Gladman DD, Urowitz MB. Single photon emission computed tomography dual isotope myocardial perfusion imaging in women with systemic lupus erythematosus: I. Prevalence and distribution of abnormalities. J Rheumatol 2000;27:2372-7.

58 Schillaci O, Laganà B, Danieli R, Gentile R, Tubani L, Baratta L, et al. Technetium-99m sestamibi single-photon emission tomography detects subclinical myocardial perfusion abnormalities in patients with systemic lupus erythematosus. Eur J Nucl Med 1999;26:713-17.

59 Sun SS, Shiau YC, Tsai SC, Lin CC, Kao A, Lee CC. The role of technetium$99 \mathrm{~m}$ sestamibi myocardial perfusion single-photon emission computed tomography (SPECT) in the detection of cardiovascular involvement in systemic lupus erythematosus patients with non-specific chest complaints. Rheumatology (Oxford) 2001;40:1 106-11.

60 Bruce IN, Gladman DD, Ibañez D, Urowitz MB. Single photon emission computed tomography dual isotope myocardial perfusion imaging in women with systemic lupus erythematosus: II. Predictive factors for perfusion abnormalities. J Rheumatol 2003:30:288-91. 